\title{
Understanding Craftsman's Creativity in a Framework of Person, Process, Product and Press (4Ps)
}

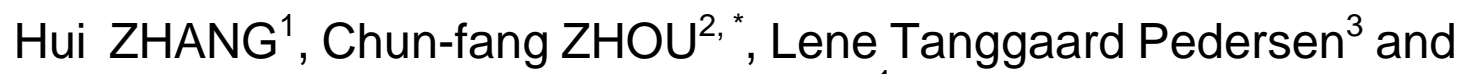 \\ Ling-ling LUO ${ }^{1}$ \\ ${ }^{1}$ Research Center for Science, Technology and Society (STS), \\ Northeastern University, 110167 Shenyang, China \\ ${ }^{2}$ Department of Learning and Philosophy, Aalborg University, 9000 Aalborg, Denmark \\ ${ }^{3}$ Department of Communication and Psychology, Aalborg University, \\ 9220 Aalborg, Denmark \\ ${ }^{*}$ Chun-fang ZHOU
}

Keywords: Craftsman, Creativity, Creativity Industry, 4Ps.

\begin{abstract}
The recent work has emphasized craftsmen are key actors in developing creative industries. However, little attention has been paid to the particular study on creativity of craftsmen. This paper aims to explore how can we understand craftsman's creativity in a theoretical framework of Person, Process, Product, and Press (4Ps)? This research question drives to develop a theoretical study bridging two areas of creativity and craftsman's work. This will further indicate craftsman's working practice is full of complexity that stimulates creative behavior and that also requires a systematic view to understand craftsman's creativity as involving interaction between 4Ps.
\end{abstract}

\section{Why to Study Craftsman's Creativity?}

Since 1950s, creativity has been a central concept in a number of disciplines, ranging from the fine arts, science, engineering, technology and architecture to psychology and management studies [1]. According to Csikszentmihalyi [2], the results of creativity enrich the culture and so they indirectly improve the quality of our lives. But we may also learn from this knowledge how to make our own lives directly more interesting and productive. Although there are a lot of definitions of creativity, a framework of 4Ps has been recognized by the scholars that means creativity is a phenomenon influenced by Personality, Process, Product and Press (or Place) [3].

Today, in development of creative industry, craftsmen are playing significant roles. In order to satisfy the demand for novelty and utility, craftsmen have to develop creativity injecting more and more creativity into the products. This means that craftsmen create something new based on inherit traditional technique to feed the social personalized needs which is different from the mass socialization mechanized production.

However, the craftsman as a kind of creative person was not paid enough attention. Up to now, only few researchers such like Sennett [4], Pallasmaa [5] and Glăveanu [6] mentioned the craftsman's creativity in their studies. However, the current research is not sufficient. Even though Sennett [4] and Glăveanu [6] mentioned craftsmen are related to creativity, they did not give explicit definition and deep analysis about how to understand craftsman's work as a creative behavior.

To consider the emergent of creative industry associated with the craftsman's creativity, this paper will fill in the current academic research gaps by focusing on 
understanding craftsman's creativity systematically from aspects of 4Ps (Person, Process, Product and Press).

\section{What is Creativity and 4Ps?}

A general definition of creativity is to develop new and useful ideas [7]. However, creativity is a highly contested concept. Treffinger and his colleagues [8] identified previous literature reviews that produced a substantial number of definitions for creativity. Negus and Pickering [9] suggest that creativity is one of the most used, and abused, terms in the modern lexicon. It comes laden with a host of meanings, connotations and applications, which are regularly imported, into a range of varying discourses, institutions and settings [10].

Further step from studies above, this paper will focus on a framework of 4Ps, which has been emphasized by scholars like Richards [11]. It means definitions of creativity can be grouped by the general scientific approaches into four main areas that were generalized as the '4Ps' [3]: the creative person, the creative process, the creative product and the creative environment ('creative press'):

- Person: understanding the traits, characteristics or attributes of the creative personality;

- Process: describing the stages of thinking that creative people use to invent something new and useful;

- $\quad$ Product: the qualities of a product which make it creative; and

- Press: the press is the environment in which the person works which may be conducive to or inhibitive of creativity.

Meanwhile, a systematic view to 4Ps was highlighted. As suggested by Hasirci and Demirkan [12], the factors such as person, process, product and press interact with each other, when a creative person uses a creative process to develop a product that exists in an environment.

\section{Craftsman's Creativity in Framework of 4Ps}

\section{A Creative Person Perspective}

The craftsmen use handmade technique to create the artifacts. Their perception, embodied cognition, manual skill, artistic sense, experience is particularly important. The craftsman has a spirit to make the best things. The tenacious personality is especially important among various kinds of idiosyncrasy. The craftsman breaks the barrier of technical rules, and produces a unique product, which is different from others. So their thinking flexibilities are strong. They have an ambition to make a product filled up with ingenuity.

Curiosity and skills have already emerged as important factors for craftsman. Action directed towards a material in a curious manner dismissive of closure is creative in the Bergsonian sense [13]. Furthermore, Sennett [4] concluded that, far from automatic action, folk artists develop a dialogue in their work between hand and head, between problem solving and problem finding. An enlightened craftsman is someone who enjoys doing creative work, develops an "intelligent hand" and a "playful mind". He falls in love with the materials and becomes so fluent in using his tools that he feels at one with them [14].

The craftsman's working experience involves the certain kind of knowledge and technical skills. The creative craftsman as a kind of technologist in a certain domain, 
contrary to what popular myth proclaims, is armed with a rich body of interconnected, dynamically changing knowledge [15].

\section{A Creative Process Perspective}

In the words of Sennett [4], every good craftsman conducts a dialogue between concrete practices and thinking; this dialogue evolves into sustaining habits, and these habits establish a rhythm between problem solving and problem finding. The characteristic of the thinking process of craftsmen can lead to different levels of creativity. Creativity is often viewed as a 'gift', while the care and skills exercised by a craftsperson are seen as a 'vocation' [5].

In the production process, the coordinate of hands, eyes and mind are more important than others. Different from the common laborers, the craftsmanship and tools are combined organic among craftsmen. The proficient level of using the technique and tools, and understanding the limits of the material at hand influence the craftsman's creative process.

The creativity is an emergent process, which involves craftsmen engaged in complex, unpredictable interactions [16]. The craftsman's creative process cannot be exactly followed, but often begins with a sense to accomplish a task or solve a puzzle. However, the creative ideas often come from destroying existing patterns of thought to produce some creative works. The craftsman's creative process often begins with the creative idea that comes to the mind before the product production, that's after the product finished, the creative process also finished.

\section{A Creative Product Perspective}

Given a historical concept of creativity, when the craftsman is the first to create a new kind of artifact, we can talk about creativity [17]. In the ancient times, the craftsmen did not care about the creativity. In contrast, they focus on how to reproduce the traditional model exactly [18]. The craftsman collaborates with the material at hand to make a unique product, which reveals creativity on the basis of existing artifacts or reveals something that did not exist before. The product is the result of the craftsman's effort to explore the beauty or utility of the material.

Meanwhile, the craftsman's products are also tied together with the personal experience, feeling and personalities. Their products are different from the mass production products, which are extremely homogeneous. Craftsmen show more creativity in the uniqueness of creation style than at the creation level. The combination of creation style and technique level is regarded as the criterion of creation.

The practicability of product exists in some industries, but not all. There are some differences between artifact and pure artwork. The pure artwork regards beauty as the only evaluation criterion. However, artifact combines aesthetic with utility, and the popularized beauty and practicability among products make normal people more like to purchase it. If the craftsman's creative product as a kind of artifact becomes famous and popular, the craftsman takes pride in his feeling of work, which can also encourage the craftsman to make novel and original products sequentially.

\section{A Creative Press Perspective}

The inner characteristics of craftsman can influence the craftsman's creativity. The craftsman often faces conflicting objective standards of excellence, and desires to do something well for its own sake. Moreover, they can be impaired by competitive pressure, by frustration, or by obsession [4]. Amabile [7] identified a number of 
"situational influences on creativity": freedom, autonomy, good role models and resources (including time), encouragement specifically for originality, freedom from criticism, and norms in which innovation is prized and failure not fatal. Unlike positive factors, some influences can also inhibit creativity. These include red tape, constraint, inappropriate norms, project management, feedback, time pressure, competition, unrealistic expectations, and a lack of respect, autonomy and resources [19].

Craftsman might have all of the inner necessities to think creatively, but without some environmental support (such as a forum for proposing those ideas), the craftsman's internal creativity may never be displayed. Families and relatives engaged in the crafts may influence the next generation to work in the same field, and the pressure for the next generation may be heavier. At the same time, craftsmen communicate with other craftsmen, get other's opinions and ideas, and interact with the surrounding environments. Even if the greatest genius need the work environment for encouraging creativity, they will not accomplish anything without the support of society and cultural.

\section{Summary: a System View}

As mentioned previously, 4Ps can be seen from a systematic view to discuss creativity. The main characteristics of the craftsman's creativity emerge from the interaction between person, process, product and press. It involves systematic efforts to create more interactive and influential ways between 4Ps. The craftsman's creativity can be understood as a system of these four factors that are related to each other. The main characteristics of craftsman's creativity include: (1) working in a favorable and free environment, (2) having a lot of relevant knowledge and skills, (3) possessing good body coordination and independent thinking ability, and (4) being responsible for taking risks to challenge tradition in order to make a unique and novel product. Each factor is an important part of the whole characteristic, and cannot be separated from the whole characteristic. The characteristics which can make craftsman more creative based on a holistic view related to the interaction among creative personality, field relevant skills and knowledge, problem solving, coordinate working process, a novel and unique product, intrinsic pressure and a supportive environment.

\section{Conclusions}

This study uses the framework of 4Ps to explore the main characteristics of craftsman's creativity. From systematic 4Ps view, it can provide us a very comprehensive understanding of craftsman's creativity.

Compared with workers in the factory, craftsmen have more living pressure; they need to face all the survival risks by themselves. However, the creative environment of craftsman is more freedom than the worker in the factory. Different from factory workers, the living environment, livelihood and culture influence craftsmen directly. The standardization, technologization and normalization on behavior pattern of craftsmen are much stronger. The influence of interaction relationship between craftsman individual and environment is changing slowly. The craftsman's historical sense, and cultural inheritance strength are strong, but the changing pressure is less.

The technology development needs the craftsman to use their creativity on certain kinds of crafts, however, if the society does not pay much attention to this kind of craft, the craftsman may contribute less on this craft, and creativity will be less used on the 
craft. The younger learn not only from elder generation but also have desires on crafts innovation to produce more creative products.

Obviously, the discussions of this paper contribute to future studies. Firstly, the research can significantly broaden our view about the field of human creativity. Secondly, the research can also tell us what kind of characteristics of craftsman may lead them to be more creative. In the future, more researches are needed on craftsman's creativity from the perspectives such as gender, culture, domain, business, and so on.

\section{Acknowledgement}

This research was one of the achievements of "Chen Changshu Technology Philosophy Development Foundation: The Demand and Mechanism Research on Domestic Enterprises Original Innovation" and supported by China Scholarship Council.

\section{References}

[1] R. J. Sternberg, Handbook of Creativity. New York: Cambridge University Press, 1999.

[2] M. Csikszentmihalyi, Creativity-Flow and the psychology of discovery and invention. New York: HarperCollins Publisher, 1996.

[3] M. Rhodes, “An Analysis of Creativity,” The Phi Delta Kappan, 42(7), pp. 305-310, 1961.

[4] R. Sennett, The Craftsman. New Haven, CT, USA: Yale University Press, 2008.

[5] J. Pallasmaa, The Thinking Hand. Chichester: John Wiley\& Sons Ltd., 2009.

[6] V.P.Glăveanu, "Rewriting the Language of Creativity: The Five A's Framework," Review of General Psychology, 17(1), pp. 69-81, 2013.

[7] T.M. Amabile, Creativity in Context. Boulder, CO: Westview Press, 1996.

[8] D. J. Treffinger, G.C.Young, E.C. Selby and C. Shepardson, Assessing Creativity: A Guide for Educators. Florida: Center for Creative Learning, Sarasota, 2002.

[9] K. Negus and M. Pickering, "Creativity and Cultural Production," International Journal of Cultural Policy, 6 (2), pp. 259-282, 2000.

[10]G. Drake, "This Place Gives Me Space: Place and Creativity in the Creative Industries, " Geoforum, 34, pp. 511-524, 2003.

[11]G. Richards, "Creativity and Tourism-the State of the Art," Annals of Tourism Research, 38(4), pp.1225-1253. 2011.

[12]D. Hasirci and H. Demirkan, "Creativity in Learning Environments: the Case of Two Sixth Grade Art-Rooms," Journal of Creative Behavior, 1, pp. 1-25, 2002.

[13]B. Liboriussen, "Craft, Creativity, Computer Games: The Fusion of Play and Material Consciousness, ”Philosophy and Technology, 26(3), pp. 273-282, 2013.

[14]S. Dasgupta, Technology and Creativity. New York: Oxford University Press, 1996.

[15]T. Thwaites, "Considering Creativity, "Pacific-Asian Education, 23(1), pp. 31-42, 2011. 
[16]R. K. Sawyer, “The Emergence of Creativity,” Philosophical Psychology, 12(4), pp. 447-469, 1999.

[17] M.E. Kronfeldner, “Creativity Naturalized,” The Philosophical Quarterly, 59(237), pp. 577-592, 2009.

[18]J. Barzun, "The Paradoxes of Creativity," The American Scholar, 58(3), pp. 337-351, 1989.

[19]M.A. Runco, Creativity, Theories and Themes: Research, Development, and Practice. London: Elsvier Academic Press, 2007. 